\title{
Improving Model of Hard Clam (Meretrix lyrata) Seed Nursing in the Coastal Area - Case Study in Tra Vinh Province, Mekong River Delta, Vietnam
}

\author{
Ta Thi Kim Oanh ${ }^{1}$, Nguyen Van Lap ${ }^{1, ~ *, ~ N g u y e n ~ T h i ~ M o n g ~ L a n ~}{ }^{1}$, Ta Duy Thong ${ }^{2}$ \\ ${ }^{1}$ Ho Chi Minh City Institute of Resources Geography, Vietnam Academy of Science and Technology, Ho Chi Minh City, Vietnam \\ ${ }^{2}$ Landscape Planning Laboratory, Graduate School of Horticulture, Chiba University, Matsudo City, Chiba, Japan
}

\section{Email address:}

ttkoanh@hcmig.vast.vn (T. T. K. Oanh),nvlap@hcmig.vast.vn (N. V. Lap), ntmlan@hcmig.vast.vn (N. T. M. Lan), Duythongtatw@gmail.com (T. D. Thong)

${ }^{*}$ Corresponding author

\section{To cite this article:}

Ta Thi Kim Oanh, Nguyen Van Lap, Nguyen Thi Mong Lan, Ta Duy Thong. Improving Model of Hard Clam (Meretrix lyrata) Seed Nursing in the Coastal Area - Case Study in Tra Vinh Province, Mekong River Delta, Vietnam. Ecology and Evolutionary Biology.

Vol. 5, No. 4, 2020, pp. 182-188. doi: 10.11648/j.eeb.20200504.20

Received: October 19, 2020; Accepted: November 30, 2020; Published: December 4, 2020

\begin{abstract}
The model of clam seed nursery in the coastal area of Tra Vinh province was carried out from June 2019 to February 2020 in the coastal dune and tidal flat in Thanh Dat Cooperative. The clam seed source is the natural seed harvested in the coast of Tra Vinh province with the goal of exploiting and using local resources to provide clam seeds for the cooperative clam farming. The model consists of two phases: the first phase of nursing is in ponds on the coastal dune and the second phase of nursing is on the tidal flat in natural condition. It indicates that during the first phase, the input of model used $50 \mathrm{~kg}$ clam grade I (150,000 ind./ $\mathrm{kg}$ ) was released into the nursing ponds, the nursing pond with oxygen supplementation is a good facility resulting high survival rate of $62.8 \%$ in comparison to $43.5 \%$ in case of pond without oxygen supplementation. In October 2019 , total $285 \mathrm{~kg}$ of grade II clams $\left(15,000\right.$ ind./ $\mathrm{kg}$ ) was obtained and released on $6,000 \mathrm{~m}^{2}$ clam ground in Thanh Dat Cooperative. In February 2020, total 2.33 million clam individuals were harvested, it is about $3,880 \mathrm{~kg}$ clam seed with the size of $600 \mathrm{ind} . / \mathrm{kg}$. The model of clam seed nursing in the tidal flat was completed with clam seed survival rate of $54.5 \%$. All of clam seed is continued culturing to the commercial clam production on the same ground of Thanh Dat Cooperative.
\end{abstract}

Keywords: Coastal Dune, Tidal Flat, Pond, Hard Clam, Nursery, Tra Vinh

\section{Introduction}

In the coastal areas, the development of aquaculture including mollusks such as clam, has made an important contribution to the national income and improved the living standards of the people. European, American and Asia countries have invested in research to rationally exploit intertidal resources to develop mollusc culture $[1,2]$. Up to now, in the world, there are works on biological characteristics, habitat, larval rearing techniques and hatchery production [3-5]. In Vietnam, researches on the development conditions of clam culture (Meretrix lyrata) have been interested, especially in the coasts and estuaries of the Red and Mekong river deltas [6-8]. In the Mekong River Delta (MRD), the Ben Tre clam (Meretrix lyrata) is widely distributed in the tidal flats in the eastern coast from Tien Giang to $\mathrm{Ca}$ Mau provinces. Clam farming is an important contributor to economic development in aquaculture in the Mekong Delta $[9,10]$. Clam products have a large export market, certified by the Marine Stewardship Council (MSC). The area for clam culture is expanded, thus demand for clam seed is higher and higher, the exploitation of seeds have been increased, so the natural clam seed source is also decreasing, not enough to provide for clam culture. Therefore, it is necessary to have research on rational use of natural resources, along with increasing investment in seed production, ensuring enough seed for production and development. Many researches on natural conditions, environment, socio-economic impacts related to clam life and the development of clam farming in the MRD have been 
carried out $[6,7,11,12]$. Results show the relationship between natural conditions and ecological environment with the appearance and development of clam, thereby proposing a model for clam resource protection and development in coastal estuaries of Tien Giang, Ben Tre, Tra Vinh [13, 14]. Tra Vinh is a coastal province in the MRD, Vietnam with about $65 \mathrm{~km}$ coastline located between the Co Chien and Bassac rivers and bordered to the East sea (Figure 1). In Tra Vinh coast, tidal flats occupy the widespread area along the coastline to $-5 \mathrm{~m}$ water depth, consisting of muddy and sandy flats. On the tidal flats, especially around the river mouths, extensive mangroves distribute and provide abundant food for aquatic species. These natural conditions are very favorable for the development of marine- brackish water aquaculture especially hard clams Meretrix lyrata. Clam farming is considered a potential aquaculture and has contributed considerably to socio- economic development of the locality. Recently, in the coast of Tra Vinh province there 9 aquaculture cooperatives with total area up to 1,125 ha, accounting for $30 \%$ of the total area allocated for clam harvesting. Similar to clam production facilities in the MRD as well as the Vietnam, clam seed is now one of the top concerns of the clam farming cooperatives in the coastal province of Tra Vinh. Every year, the occurrence of natural clam seed at the clam ground as well as coastal tidal flats is often unstable in terms of density as well as distribution space. The presence of large amounts of natural clam seed is consistent with the presence of adult clam in the range of 8090 ind./ $\mathrm{kg}$ and clam parents in the clam ground and low flood water level in the Mekong River [7, 11]. The clam seed source annually occurs in main crop from May - August and a second crop with a small amount also appeared in December - February next year. Around September, due to unfavorable natural conditions such as hydro- marine coastal regime, fresh water coming from upstream, wind and coastal currents... adverse impacts on clam seed such as dead or washed away, thus, clam seed should be taken away of tidal flats to keep in safe places. When the clam seed appears, cooperatives exploit and sell whole them on the clam grounds. In the natural tidal flats, local people and others come to spontaneous exploitation, disputes and surrender beyond the control limits... thus significantly reducing the quantity and quality of the clam seed exploited. Most of the clam seed harvested in the coastal area of Tra Vinh province is sold and transferred to the clam fishery of Ben Tre province, where it is cultured into clam and supplied to clam production facilities including Tra Vinh province [15].

Nursing clam seed in the coast of the MRD has also been considered [16-18]. In Tra Vinh province, a model of clam seed nursery in the coastal area was implemented in 2016 to 2017. The clam seed source was natural seed harvested in the coastal area of Tra Vinh province. Total $30 \mathrm{~kg}$ of clam seed of grade I $(150,000$ ind./ $\mathrm{kg})$ was released into the nursing pond. In February 2017, there were a total of 2.4 million clams with 600-650 individuals. / $\mathrm{kg}$ has been harvested [6]. Although the survival rate is high at $70 \%$, this is the first trial. Therefore, it is necessary to have follow-up experiments, research on seed nursing model in order to effectively exploit the clam seed resources and supplying clam seeds to local clam Cooperatives. This paper is the result of a clam nursing model conducted in Thanh Dat Cooperative from June 2019 to February 2020, using $50 \mathrm{~kg}$ of natural clam seed collected at the tidal flats in Tra Vinh province. Two phases are carried out on the coastal sand dune with and without the nursing pond with oxygen supplementation, and the second phase is on the tidal flat.

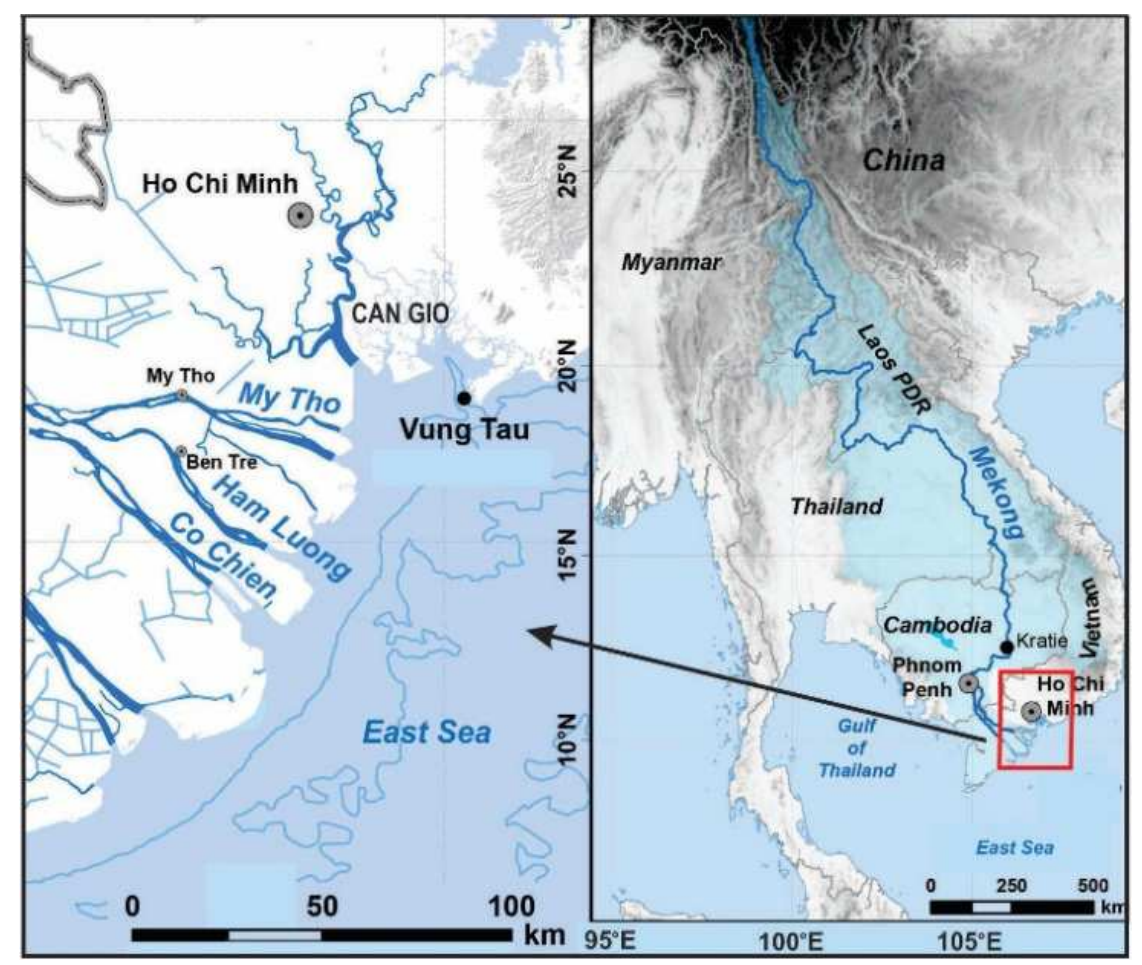

Figure 1. Location of Tra Vinh province in MRD Vietnam. 


\section{Materials and Method}

\subsection{Field Survey and Data Collection}

Selecting the suitable place in the coast sand dune and tidal flat for establishing model.

Collecting samples of water, bottom sediment at 6 station on the tidal flat; monitoring salinity, temperature and $\mathrm{pH}$ (HORIBA-Japan Field Measurement).

\subsection{Analysing in Laboratory}

Factors of environmental quality (DO, BOD5, Chlorophyll-a, TSS, TN, TP, TC) in water, sediment samples are analysed according to current research norm from HCMC Institute of Resources Geography (HCMCIRG), Vietnam Academy of Science and Technology (VAST).

\subsection{Materials}

$50 \mathrm{~kg}$ of natural clam seed with grade I $(150,000$ ind./ $\mathrm{kg})$ harvested in Tra Vinh coastal area.

\section{Results and Discussion}

\subsection{Climate, Hydro - Marine Characteristics Related to the Nursing Model of Clam Seed}

The coastal area of Tra Vinh province has a tropical monsoon climate near the equator, with two rainy and sunny seasons. The sunny season from November to April with the main wind direction is east and northeast; rainy season from May to October with southwest monsoon; Total annual rainfall is about $1,200-1,450 \mathrm{~mm}$. The rainy season is characterized by more persistent and strong winds as well as a larger tidal range compared with the dry season when met-ocean forces are subdued. Fresh water input into the river mouths during ebb tides results in dilution of the water, increase in the volume of water discharge and increased current speed. While seasonal variations affect the tidal range at the river mouths during dry and wet seasons, the currents and water fluxes of river mouths vary with the seasons. Significant tidal incursions exist in the coastal area during rainy and dry seasons. During rainy season, the salt wedge moves seawards while during the dry season and high tide, the salt wedge moves inland. The tidal variations superimposed by the freshwater discharge create plume areas in the sea off these river mouths. These plumes, which are heavily laden with sediments, are more prevalent especially during low tides when fresh water input extends farther out into the sea, and partly shifting southwest ward to the $\mathrm{Ca}$ Mau cap owing to longshore current, particularly in the northeast monsoon. The annual average temperature is about $26.6^{\circ} \mathrm{C}$, the lowest is about $25^{\circ} \mathrm{C}$ in January and the highest in April is about $29-32^{\circ} \mathrm{C}$, which has a significant impact on aquaculture, especially the coastal clam [6].

Oceanographic parameters that control circulation patterns on the coast and ocean consist of waves, tides and longshore currents, with wind and salinity modifying these oceanographic processes. Waves affecting the coastal area are wind-generated and approach the coastline from a southwest direction. The wind systems consist of the onshore southwest and offshore north east.

Tides within the coastal area are semi-diurnal with two inequalities. Elevated water, close to the shore during the two daily high tides, generally assists the waves to progress further inshore. The semi-diurnal tide regime has a range of about 2.9 to $3.4 \mathrm{~m}$ with the lowest tide of about $-2.5 \mathrm{~m}$ to $-1.7 \mathrm{~m}$ and the highest tide of about $1.0 \mathrm{~m}$ to $1.6 \mathrm{~m}$. Maximum monthly tidal range is about $2.7-3.5 \mathrm{~m}$ and tends to decrease from Cung Hau to Dinh An river mouth, so the currents and tidal currents are generally oriented from northeast to southwest [7].

In the southwest monsoon, windless condition combined with weak tide current, low tide amplitudes and weak waves are good conditions for the formation of clam seed landing field [14, 19]. In contrast, the high speed north-east wind reaches the maximum of $5-8 \mathrm{~m} / \mathrm{s}$ in February-March, creating high waves and strong currents, causing bank erosion, disturbance of the tidal flat bottom to be a cause of clam death.

Tidal flats have exposure time of about $8-14$ days per month and about 2 - 6 hours per day depending on the tide level. Water depth in clam ground is about $3-3.2 \mathrm{~m}$ so it is less affected by hot sunlight.

Water temperature of the clam ground with fine sand composition is higher than in the mud flats and in deep water. Average monthly sea water temperature is about 26.1 $30.0^{\circ} \mathrm{C}$ in daytime and $25.5-29.5^{\circ} \mathrm{C}$ at night. Seasonal transitional periods are an important condition that stimulates the reproduction and growth of clam larvae from May to August annually. In addition, the northeastern-southwestern current is the main cause of the decrease in temperature from north to south.

Water salinity of clam ground varies considerably between 1.3 and $30.2 \%$. Salinity is low in the rainy season, the lowest is about 1,3 - $3 \%$ in September - October and the highest is about $32.4 \%$ in April. Water salinity of clam ground is suitable for clam live and grow [12]. Depending on the location near or far from estuaries and the size of the living clams, significant changes in salinity affect in clam grounds.

In September - October, muddy deposition usually occurs in the clam ground [7]. In extreme weather condition, the effect of low pressure in the northeast monsoonal season, mud layers about $10-30 \mathrm{~cm}$ occupy on the troughs, coastal and low parts of the intertidal zone about 5-8 days/ time, can cause clam death so it is necessary to forecast and move clams to a safe place [14]. Every year around October November, the treatment of shrimp ponds discharges into the sea of large amount of sludge and waste water affecting to the environment of coastal clam ground.

\subsection{Ecological Characteristics of Water and Sediment of Thanh Dat Clam Ground}

Thanh Dat cooperative was selected to implement the 
second stage nursing on the tidal flats. Samples were collected at six stations (Figure 2) in the period of 06/2019, $11 / 2019$ and $03 / 2020$. Research on the ecological characteristics of water and sediment environments was conducted.

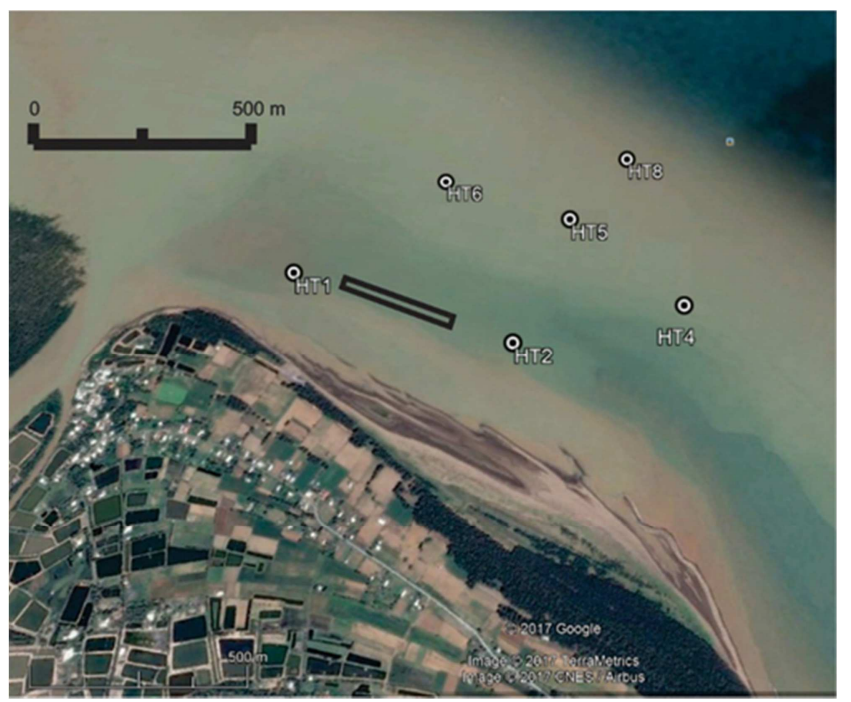

Figure 2. Clam seed nursing in the tidal flat and sampling locations.

Nutritional salts and total N, P in water environment

The results of analysis of inorganic nutrient elements in water environment showed that Thanh Dat cooperative has significantly affected river water. Large fluctuations in $\mathrm{NH}_{4}$ and $\mathrm{NO}_{3}$ show the effects of seasonal river flow (dry and flood season) on the ground. In the dry season (March) average $\mathrm{NH}_{4}$ content was about $48.5-120.0 \mu \mathrm{g} / \mathrm{l}$, and $\mathrm{NO}_{3}$ was 118.5 - $204.7 \mu \mathrm{g} / \mathrm{l}$, and $\mathrm{NO}_{2}$ was about $16.2-36.5 \mu \mathrm{g} / \mathrm{l}$, and increased in the rainy season (June) with values of 142.0 - $337.0 \mu \mathrm{g} /$ 1, 295.0 - 327.5 and 24.6 - $60.2 \mu \mathrm{g} / 1$, respectively. At the end of the rainy season (November), the $\mathrm{NH}_{4}$ and $\mathrm{NO}_{2}$ content decreased and were respectively 50.4$175.6 \mu \mathrm{g} / 1,17.5-24.6 \mu \mathrm{g} / 1$, but $\mathrm{NO}_{3}$ remained high value is $378.6-492.8 \mu \mathrm{g} / 1$. Inorganic nutrient salts in water of this area is quite abundant, which is a good condition for phytoplankton to grow during photosynthesis.

Total nitrogen (TN) and total phosphorus (TP), were 793 1575 and $68-257 \mu \mathrm{g} / 1$, respectively, suggesting that $\mathrm{TN}$ is higher than TP and usually reaches its maximum in mid-March. Total Suspended Solids (TSS) content is generally high at between 52.50 and $217.45 \mathrm{mg} / 1$.

Bio-chemical characteristics of sea water

The results of DO analysis show that the clam ground area is quite good (average DO $>6 \mathrm{mg} / 1$ ), but the changes of BOD5 content indicate the organic content decomposes easily in water, the BOD5 content is usually 1.28 to $2.75 \mathrm{mg} /$ 1. Raw biological productivity values are quite high, about $45.8-427 \mathrm{mgC} / \mathrm{m}^{3} /$ day, and are usually high in June because of the large amount of inorganic nutrient salts fed by inland rivers. The POC content is about $115-467 \mu \mathrm{g} / 1$, the Chl-a with a high content of about $4.25-12.25 \mu \mathrm{g} / \mathrm{cm}^{3}$, indicating the abundance of phytoplankton is an appropriate condition, source of food for many species of zooplankton, benthic organisms such as clam. The results show that in addition to the presence of carbon content of phytoplankton, there is also a large amount of organic carbon derived primarily from humus residues fed by river into coastal waters [7]. The surficial deposits of the sandy tidal flats have been varied seasonally. In the rainy season, the clam ground often is accumulated by a layer of muddy liquid brought by the river. This phenomenon depends on the amount of silt and the impact of current from the river mouth, as well as topography of the tidal flats. In the northeast season, especially during the extreme weather, the surface of the clam ground is often covered by a muddy layer. Ecological characteristics and seasonal changes of bottom sediment affect to the density, growth rate and distribution of clam. Clam farming ground is usually covered by mud in 3 to 6 days, clams are often buried deep themselves in sand safely, however clams will die if the muddy fill time is longer so it is necessary to remove clams to the appropriate location.

The bottom layer of clam ground is mainly composed of sand, fine sand, silty sand with a little mud and organic matter. The clam is mainly distributed on the mid-intertidal and high part of sub-tidal areas in the coastal sandy tidal flats that are mainly characterized of $80-90 \%$ sand, $9-14 \%$ mud and organic fragments. On the surface, deposits make easy for the burrowing of clams, the buried depth is about 4-6 cm below the bottom layer of the sandy flats. The typical environmental factors of the clam ground vary markedly seasonally, depending on the upstream rainfall and flooding as these conditions alter salinity as well as the natural conditions associated with the facility of clam feed. Therefore, the bottom is an important ecological factor affecting the survival and development of mollusks, and is a food source for aquatic life. Geomorphology and sediment of the intertidal flats often change due to seasonal sedimentation in the year, especially in the northeast monsoon, mud filling occurs on most of the tidal flats, which is one of the causes of rish of clam. In March to May prolonged heat often causes the death of clam, in addition the discharge of sludge and wastewater from shrimp ponds significantly affected the environment of clam grounds in the Tra Vinh province. The content of TOC and TN in the sediment of the clam culture site is about 0.48 to 14.85 and 0.42 to $3.85 \mathrm{mg} / \mathrm{g}$; Chl-a is generally about $0.82-14.07 \mu \mathrm{g} / \mathrm{cm}^{3}$ indicating the abundance of phytoplankton; Oily content was not detected to low at 1.6 - $20.5 \mu \mathrm{g} / 1$. This shows that organic sludge and humus accumulate quite large, thus facilitating the feeding of organisms. However, this is disadvantage because it creates a reducing environment which is detrimental to farming clam.

\subsection{Establishing a Clam Seed Nursing Model}

The clam seed used in this model was collected from the natural clam seed source in Tra Vinh coastal area. The model of clam seed nursing is composed of two phases at Thanh Đat clam farming cooperative: the first phase is carried out in the nursing pond on the coast and the second phase is on the natural environment of tidal flat.

Phase 1: Nursing of clam seed in pond on the coast 
Model location: Natural seed clams are collected in Tra Vinh coastal area. Due to the favorable appearance of clam seed and weather conditions, we made twice of collecting clam seeds, about $50 \mathrm{~kg}$ each stage in about 8 days and nursing.

Construction and installation of nursing ponds

The nursing ponds and water supply ponds are built and installed on coastal sand dunes with a topography of about 3.4 to $3.6 \mathrm{~m}, 350-400 \mathrm{~m}$ from the sea and shielded by casuarina trees.

Nursing ponds are dug in the sand dunes and three demensions of $40 \times 8.0 \times 1.0 \mathrm{~m}$, bank height is about 0.8 $1.0 \mathrm{~m}$, total 04 ponds. Ponds are lined with double-skinned canvas and installed with pipes (114- $150 \mathrm{~mm}$ diameter PVC pipes) to supply and discharge water.

A water- supply pond is about $5,000 \mathrm{~m}^{2}$ with $1.8-2.0 \mathrm{~m}$ deep that is improved from shrimp pond. This pond is connected to the sea via a channel of about $350-400 \mathrm{~m}$ in length. Seawater is collected and stored in this water supply pond to stabilize the $\mathrm{pH}$, salinity and water temperature indices in accordance with the growth of seed clams. Periods of continuous rain or hot sunshine days make change salinity and temperature of pond water that will adversely affect to the size of clam seed or cause clam seed death. Therefore, the stabilization of $\mathrm{pH}$, salinity and water temperature indices in the water supply pond is done through the appropriate opening and closing of the canal.

Water from water- supply pond is pumped into nursing ponds, which is the habitat and source of feed for seed clams, at the same time water discharge from nursing ponds will help to clean ponds that contribute importantly to the growth of seed clams. The nursing pond bottom is sanded with thin layer of clean and fine sand (from local tidal flat) with a thickness of 5-6 mm on the bottom.

Releasing clam seed and organizing nursing

Natural clam seed are released into nursing ponds. The quantity and size of clam seed in twice releasing:

First time: In June 09th, 2019, $30 \mathrm{~kg}$ clam seed were dropped down pond No. 1 with size 150,000 ind./ kg;

Second time: In July 12th, 2019, $20 \mathrm{~kg}$ clam seed were dropped down pond No. 2 with size 150,000 ind./ kg;

The monitoring and care of seed clams are as follows:

Water in nursing ponds is pumped from the water supply pond and replaced by new water after 1- 2 days of use. Every time of changing water, about three-quarters of the water in the pond is drained to the canal and the same amount of new water is added from the water- supply pond.

Water in nursing ponds was measured $\mathrm{pH}$, temperature and salinity indices, at once the sandy layer of bottom temperature was also checked, especially on hot days. Results showed that water in nursing ponds usually have suitable indices such as temperature of $28.4-31.6^{\circ} \mathrm{C}$, salinity 10.7- $16.5 \%$, $\mathrm{pH} 6.85-7,95$; and the temperature of sandy layer is about $29.8-31.7^{\circ} \mathrm{C}$.

Along with the water change is to spread a small amount of fine sand on the bottom of the nursing pond. This is clean, fine sand and free from flakes, shell fragments as well as decomposed organic matter.

After about 25 days of observation, the clam in pond No. 1 was divided into two equal amounts of which transfer into the pond No. 3 and the half amount is remained at the pond No. 1 to ensure the available conditions for clam seed growth.

Continue to pump water from the water- supply ponds to the nursing ponds and change water twice a day.

At the same time spread an amount of new clean, fine sand on the nursing pond bottom, once a day. On September 7th 2019, all seed clams with size 45,000- 46.000 ind./kg from nursing ponds No. 2 and 3 were transferred to pond No. 4 with oxygen supplementation. The nursing pond has aerator to stabilize the nursing environment, increase the growth of clams and reduce the risk of clam seed death. Oxygen supplementation was studied during the model implementation (Figure 3). meanwhile, the pond No. 1 is taken care of normal condition without an oxygen supplementation.

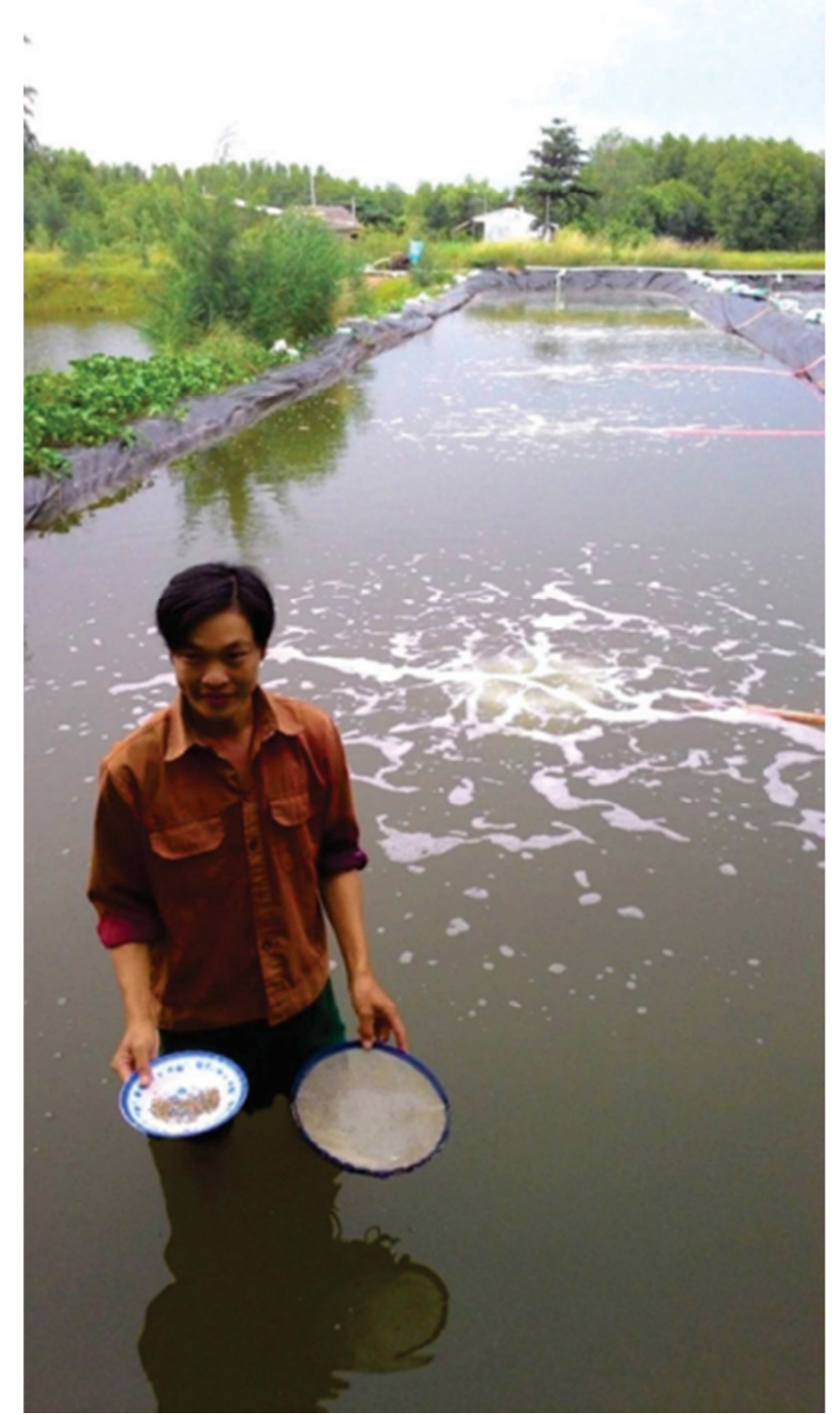

Figure 3. Nursing pond with oxygen supplementation. 
Indices of water in nursing pond were measured and monitored with water temperature of $31.6^{\circ} \mathrm{C}$, salinity of 12.5\%, $\mathrm{pH}$ : 7.86; Sand layer temperature of $31.2^{\circ} \mathrm{C}$. Water supply with temperature $30.9^{\circ} \mathrm{C}$, salinity $14.2 \%$, $\mathrm{pH}$ : 8.11 . After 4 months of nursing, clam seed size reached 15,000 ind./kg, the first nursing stage ended and seed clams in nursing

pond are harvested and using the net to remove the clam seeds from the sand. On October 24, 2019, harvesting clam seeds in nursing ponds, there are $285 \mathrm{~kg}$ clam seeds with the size of 15,000 ind./ $\mathrm{kg}$ (Figures 4, 5) in total of both ponds in which there are $220 \mathrm{~kg}$ reaching $62.8 \%$ in the pond No. 4 , meanwhile only $65 \mathrm{~kg}$ reaching to $43.5 \%$ with survival rate in the pond No. 1.

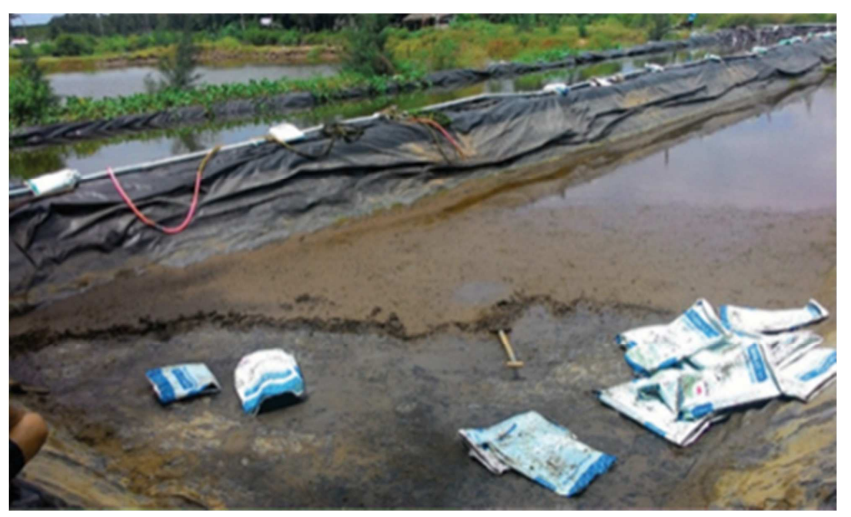

Figure 4. Harvesting clam seed.

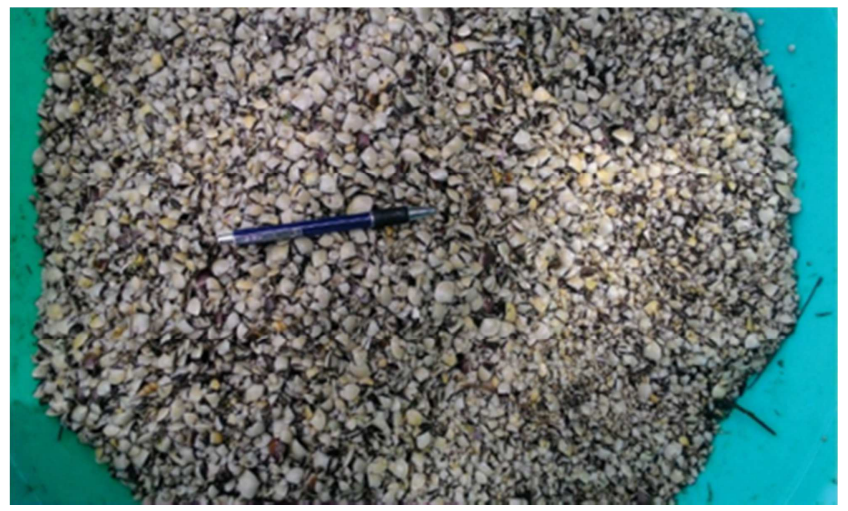

Figure 5. Harvesting clam seed in nursing pond with 15,000 ind./kg.

This experiment indicates that there are some damages occur in the nursing pond without oxygen supplementation and clam seed death is also detected in this period. Consequently, the survival rate is $43.5 \%$ to be low in comparison with $62.8 \%$ in the nursing pond with oxygen supplementation.

Phase 2: Nursing in natural tidal flats

According to the plan, on October 25, 2019, total $285 \mathrm{~kg}$ clam seed were released to $6,000 \mathrm{~m}^{2}$ area of tital sand flat of Thanh Dat cooperative. Topography of tidal flat is quite flat, convenient for care and nursing, the area is about $6000 \mathrm{~m}^{2}$ $(300 \times 20 \mathrm{~m})$ and far from the coast about 450-500 $\mathrm{m}$ (Figure 2 ). The clam nursing ground was cleared of mollusc shell, leveled before the releasing clam seed $[14,15]$. The indices of water and sediment environment of this ground meet requirements for the growth of clam seed. The seed clams were cared, thinly scattered and checked their growth with the following results:

1. 25/10/2019: Releasing $285 \mathrm{~kg}$ clam seed with size 15,000 ind./ $\mathrm{kg}$ to the tidal sand flat of clam ground, about 710 ind. $/ \mathrm{m}^{2}$ in density.

2. 24/11/2019: Clam seed size reached about $8,000-9,000$ ind. $/ \mathrm{kg}$

3. 07/12/ 2019: The size is about 4,000 - 5,000 ind./ kg;

4. 21/12/ 2019: The size is about $1,500-2,000$ ind./ kg;

5. 19/01/ 2020: The size is about $700-800$ ind. $/ \mathrm{kg}$;

6. 24/02/ 2020: The size is about 580 - 600 ind./ $\mathrm{kg}$ (Figure 6) the number of 2.33 million individuals, it is about $3,880 \mathrm{~kg}$ clam seeds.

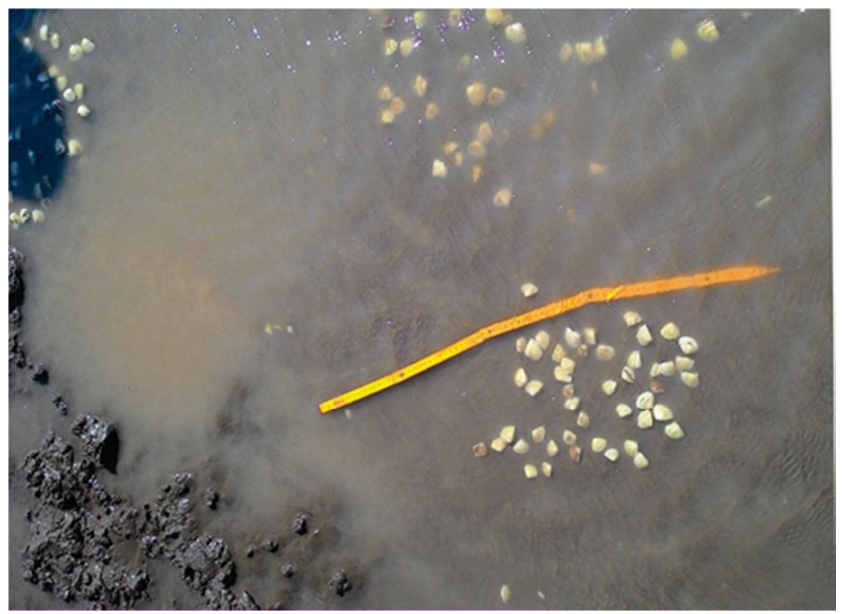

Figure 6. Harvesting clam seed in the tidal flat with $600 \mathrm{ind} . / \mathrm{kg}$.

The second phase of clam seed nursing in the tiadal flat was completed with clam seed survival rate of $54.5 \%$. All of clam seed is continued culturing to the commercial clam production on the same ground of Thanh Dat cooperative.

\section{Conclusion}

The model of nursing clam seed originated from natural clam seed in Tra Vinh coast has been developed successfully. The model consists of two phases: the first phase of nursing in ponds on the coast sand dune and the second phase of nursing on the tidal flats in natural condition. It indicates that during the first phase, the nursing pond with oxygen supplementation is a good facility resulting high survival rate of $62.8 \%$ in comparison to $43.5 \%$ in case of pond without oxygen supplementation.

The ecological characteristics of the water, bottom sediment environment of the clam ground of Thanh Dat cooperative were favorable to carry out the second phase of clam seed nursing on the tidal flat, they were suitable for the growth of cultivating seed clams.

Result of the model shows that total $50 \mathrm{~kg}$ of natural clam seed $(150,000$ ind./ $\mathrm{kg})$ were released in nursing pond on the sand dune, nursing stage on the tidal flat: $285 \mathrm{~kg}$ clam seed $(15,000$ ind./ $\mathrm{kg})$ were released on tidal flat area of $6,000 \mathrm{~m}^{2}$, 
after 4 months harvesting 2.33 milion individuals with size of 600 ind./ $\mathrm{kg}$, reaching $54.5 \%$ survival rate.

\section{Acknowledgements}

We sincerely thank MOST grant from Vietnam (Grant Number KC.09.35/16-20) for funding and facilitating the implementation of the project. Thanks for the cooperation of Thanh Dat Cooperative in Tra Vinh Province.

\section{References}

[1] Higano, J., Influence of environmental changes in the tidal flats on the filtration and respiration of bivalve mollusks. Bull. Fish. Res. Agen, 2004, Supplement No. 1, 33-40.

[2] Marinov D., Galbiati L., Giordani G., Viaroli P., Norro A., Bencivelli S.. An integrated modelling approach for the management of clam farming in coastal lagoons. Aquacuture, 2007,269 , p. $306-320$.

[3] Gosling E. M. Bivalve Molluscs - Biology, Ecology and Culture, Blackwell Publishing, USA, 2003, pp 439.

[4] Helm M. M., Bourne N., Lovatelli, A.. Hatchery culture of bivalves a practical manual. FAO fisheris technical, 2004, p. 471. Food and agriculture organization of the United Nations, Rome.

[5] Quayle, D. B., G. F. Newkirk. Farming bivalve molluscs: methods for study and development. Advances in World Aquaculture, v. 1. Baton Rouge, LA: World Aquaculture Society in association with the International Development Research Centre, 1989, 294 p.

[6] Nguyen TA, Tran TTN. Scientific evidence of a number of solutions to protect and develop resources of clams and cockles in the coastal tidal flats of Ben Tre province (in Vietnamese). Project final report, People's Committee of Ben Tre Province Nha Trang Institute of Oceanography. 2001, 216 p.

[7] Ta TKO, Nguyen VL, Nguyen TML, Ta DT, Vo THQ. Natural and environmental characteristics of Tra vinh province coastal areas, Mekong Delta, Vietnam for the development of hard clam culture. Journal of Biodiversity and Environmental Sciences. 2018, 11-20.

[8] Nguyen XD. Resources of mollusc species Meretrix and Mactra in the intertidal area of Nam Dinh and Ninh Binh provinces (in Vietnamese). Scientific workshop: Sustainable management and use of natural resources and environment of coastal estuarine wetlands - Hanoi, Publisher of Agriculture. 1999, 37-41.

[9] Huynh VH. Distribution of benefits and costs in the white clam value chain (Meretrix lyrata, Sowerby, 1851) in Tra Vinh province (in Vietnamese). Proceedings of Conference "Relationship between mangrove forests and clam resources", Ho Chi Minh City 11/2014, 110-120.
[10] Le XS, Do MC, Huynh VH, Truong QP. Marketing study to support the development of hard clam industry in Tra Vinh province in relation to the southern coastal provinces (in Vietnamese). Journal of Science, 2007, 8, 38 - 46, Can Tho University.

[11] Vo ST. Investigation on ecological - environmental conditions and developing ability of Clam (Meretrix lyrata) in Go Cong district - Tien Giang province. Project final report (in Vietnamese). Institute of Oceanography, Nha Trang, 1999.

[12] Nguyen VH, Nguyen DH, Pham CT, Tran QM, Nguyen TT. Research on some environmental indices, biological characteristics and clam Meretrix lyrata (Sowerby, 1851) resources in the Mekong Delta (in Vietnamese). Proceedings of The first national conference on mollusk. Publisher of Agriculture. 2001, 176-189.

[13] Tong PHS, Nguyen TT. The relationship between natural conditions and the formation and development of clam grounds (Meretrix lyrata) in the Mekong Delta. Chapter 18 in Environmental change and agricultural sustainability in the Mekong Delta, Advances in Global Change Research 45, Springer Science + Business Media B. V., 2011, 303-333.

[14] Nguyen TT. et al. Study on the model of protection and development of clam resources Meretrix lyrata (Sowerby, 1851), cockle Andara granosa (Linaeus, 1758) in Tien Giang, Ben Tre, Tra Vinh estuarine coastal areas. Project final report (in Vietnamese), Department of Science and Technology. 2010, 197 pages.

[15] Ta TKO, Nguyen VL, Nguyen TML. Study on hard clam (Meretrix lyrata) seed nursing model in the coastal areas of Tra vinh province, Mekong Delta, Vietnam. Journal of Biodiversity and Environmental Sciences. 2018, 11-20.

[16] Nguyen DH, et al. Research on clam seed production (Meretrix lyrata Sowerby, 1851). Proceedings of The third national conference on mollusk. Publisher of Agriculture, 2003, $100-114$.

[17] Nguyen HP. Biological characteristics and tecniques of nursing clam (Meretrix lyrata, Sowerby) (in Vietnamese). Aquaculture Science and Technology Information $7 \&$ 8. 1996, 13-21 and 14-18.

[18] Chu CT and Kumar MS. Clam (Meretrix lyrata) hatchery manual. Manual report collaborative research between the South Australian Research and Development Institute (SARDI) and Aquaculture Research Sub-Institute for North Centre (ARSINC). 2008, 34 pages.

[19] Nguyen VH. The characteristics on biology and production of Clam (Meretrix lyrata) in Mekong Delta. (in Vietnamese) Proceedings of scientific conference "Bien Dong" 2000, pp 219-230. 